\title{
Technical note: Preparation improvement of charred cadaveric viscera using sandison's rehydrating solution for histological analysis
}

\author{
Guendalina Gentile ${ }^{a}$, Alessio Battistini ${ }^{\mathrm{a}}$, Salvatore Andreola ${ }^{\mathrm{a}}$, Michele Boracchi ${ }^{\mathrm{a}}$, \\ Matteo Marchesi ${ }^{\mathrm{b}}$, Stefano Tambuzzi ${ }^{\mathrm{a}}$, Riccardo Zoja ${ }^{\mathrm{a}, *}$ \\ a Dipartimento di Scienze Biomediche per la Salute, Sezione di Medicina Legale e delle Assicurazioni, Università degli Studi di Milano, Via Luigi Mangiagalli, \\ 37, 20133 Milano, Italy \\ ${ }^{\mathrm{b}}$ Azienda Socio-Sanitaria Territoriale Papa Giovanni XXIII Piazza OMS, 1 Bergamo, Italy
}

\section{A R T I C L E I N F O}

\section{Article history:}

Received 19 July 2019

Received in revised form 7 October 2019

Accepted 14 November 2019

Available online 16 November 2019

\section{Keywords:}

Charring

Hyperthermal lesivity

Sandison"s rehydrating solution

Forensic pathology

Histology

\begin{abstract}
A B S T R A C T
In forensic evaluation of charred corpses, internal detrimental signs may result as more significant of those observed during external examination and is often arduous to state if a victim was exposed to fire before or after death. When the histological analysis of the remaining internal viscera is necessary, the massive destruction caused by the lesion, the charring and the coarctation of the samples don't allow to give further information or to determine the remaining organic components of the viscera. This limit is determined by the intrinsic characteristics of this thermal lesivity of self-maintenance even after the exitus of the subject, worsening the initial detrimental framework. The Authors, with the purpose of improving the microscopic visualization of the samples collected from cadavers with peculiar deterioration, as in case of carbonization, suggest the use of a specific technical protocol based on the use of Sandison's rehydrating solution since the samples treated with this solution showed, at microscopic examination, a substantial histological-morphological improvement.
\end{abstract}

(C) 2019 Elsevier B.V. All rights reserved.

\section{Introduction}

Charring is the most severe stage of the lesions caused by the exposition of the tissues to very high temperatures through the direct effect of a flame. Generally, this detrimental mean causes a darkening of the skin and a dry aspect of its surface, sometimes leaving spot-size areas untouched [1]. The cadaver shows the characteristic aspect of the "fighter" due to the forced musculartendinous contraction and self-amputation of the limbs is possible [2]. When charring is extended to the deep tissues [3] a volumetric reduction of the internal organs caused by dehydration, lesions due to expansion of intracavitary gasses and coagulative cataract can be observed.

Autopsy examination on these cadavers is arduous under several aspects, such as for personal identification, for chronological determination of the lesions observed - in order to collocate them ante- or postmortem-, for stating the dynamic of the events in order to discriminate between accident, suicide [4] homicide/ cadaver's destruction [5] and, finally, for identifying the type of propellant used as a primer [2].
On the charred corpse, the microscopic examination can be particularly difficult since not only the fragile, disrupted and extremely dry tissues can be easily lost during standard histological processing, but also because the few histological slides obtained are characterized by frequent technical artifacts.

The Authors have applied, for the first time ever, the Sandison's rehydrating solution on charred cadaveric tissues in order to assess whether its application could improve the histological architecture of both cadaveric skin and internal organs. The procedure proved to be useful and effective, allowing us to obtain higher quality histological sections - reduction of the destructive thermal effects - compared to the equivalent ones obtained following the tissue fixation only in formalin. In this study, therefore, we present the microscopic findings achieved after the application of this technique.

\section{Materials and methods}

We have considered 22 charred corpses (Fig. 1) that underwent judicial autopsy at the Bureau of Legal Medicine of the University of Milan between January 2016 and June 2018.

\footnotetext{
* Corresponding author at: Sezione di Medicina Legale, Università degli Studi, Via Luigi Mangiagalli, 37,20133 Milano, Italy.

E-mail address: riccardo.zoia@unimi.it (R. Zoja).
} 


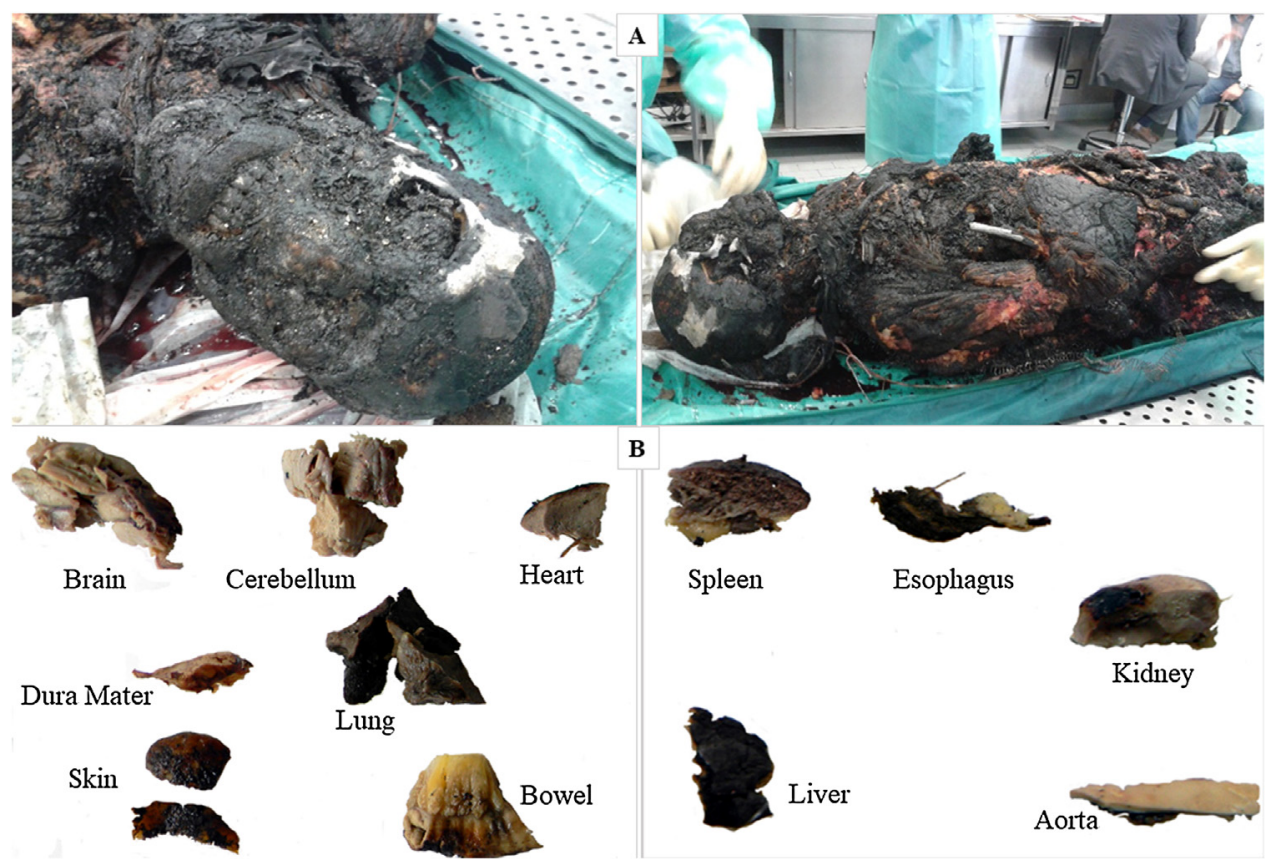

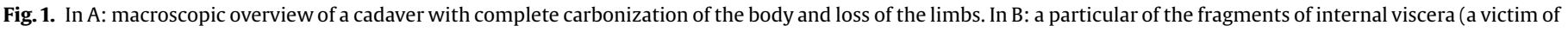
charring in a car due to accidental explosion of the gas tank).

The victims, with an age range from 21 and 86 years, were all Caucasian exception made for one corpse of Negroid race. The corpses enrolled in the study belonged to 18 males and 4 females deceased because of accidents in 14 cases, suicide in 5 cases and homicide in the remaining 3 cases. On the whole, we sampled 59 fragments of skin ( 9 from the scalp; 3 from the neck; 12 of thoracic skin; 6 of abdominal skin; 17 of skin of the upper limbs and 12 of skin of the lower limbs) and 72 fragments of internal organs. In both cases, the sampling was performed in correspondence of the areas affected by macroscopic lesions caused by excessive heat. (Table 1)

The 131 biological samples, with dimensions of $2.0 \times 0.5 \mathrm{~cm}$, were samples in double (with a total amount of 262 samples) and underwent two different procedures: the first half (samples A) was directly fixated in $10 \%$ buffered formalin while the other half (samples B) was previously treated for three days with Sandison's rehydrating solution and then fixated in $10 \%$ buffered formalin. After fixation, all samples were dehydrated with standard procedures for $20 \mathrm{~h}$ in an automatic histological processor thanks to increasing ethanol solutions, clarified with xylene substitute and embedded in paraffin with high meltig point $\left(65-58^{\circ} \mathrm{C}\right)$. From all the samples we cut out 2 - $\mu$-thick slides by means of a Reichert microtome and we stained one of them with H\&E staining and the other one with Masson-Goldner's trichrome technique. The latter histochemical staining, being able to well differentiate connective tissue from muscular tissue, was used in order to better evaluate the potential rehydrating effect of Sandison's solution. Finally, the obtained slides were observed with a Leica DMR microscope and the most significative areas were photographed with a Leica DC300 F digital camera.

\section{Results}

Microscopic observation of charred tissues treated with the two different procedures (Group A with standard fixation and Group B pretreated with Sandison's rehydrating solution) has revealed important results.
Samples belonging to Group A showed morphological and structural alterations typical of this type of lesivity, such as various artifacts resulting from drying/charring of the structures, widespread deposits of blackish matter, structural irregularities, wide areas of complete destruction of the prepared slides, detachment and loss of several portions of histological slides and altered tissue stainability.

Vice versa, samples belonging to Group B showed a significant improvement of the general histological architecture, lacking of the typical destructive effects characterizing this kind of lesion.

The main morphological and structural differences between these two groups are reported divided in three major categories: tegument, parenchymatous viscera and hollow organs.

\subsection{Tegument}

We analyzed samples of skin

In formalin, presence of wide areas of charring of the epithelium, of the dermis, of the superficial portions of the subcutaneous adipose tissue and of the tissue surrounding the muscles. In few spared areas, epithelium with marked coagulative effects, partial detachment of the dermal connective tissue and separation of the muscular fibers. A severe coagulation of the glands of the adnexa could be noted along with an alteration in stainability (pronouncedly basophilic) with a brownish-blackish coloration, wide lacerated areas and extensive protein coagulation. In the context of muscular tissue, several contraction band necrosis areas could be observed. Pre-treatment with Sandison's rehydrating solution showed a visible improvement of the general morphology of the tissue: the epithelium resulted to be conserved and well recognizable nonetheless a marked dissociation of the connective fibers of the dermis could be noted. Sub-epithelial connective tissue showed few ripples and the vascular structures resulted to be recognizable. Only focal areas of muscle fibers degenerative phenomena could be highlighted along with a modest volumetric reduction of the fibers themselves and confluent pyknotic nuclei (Fig.2). 
Table 1

General presentation of the sampling assessed on charred corpses.

\begin{tabular}{|c|c|c|c|c|c|c|c|c|c|c|c|}
\hline \multirow[t]{2}{*}{ N. Case } & \multirow[t]{2}{*}{ Age } & \multirow[t]{2}{*}{ Sex } & \multirow[t]{2}{*}{ Manner of death } & \multicolumn{8}{|c|}{ Biologic sample } \\
\hline & & & & Skin* & Brain & Lung & Heart & Liver & Spleen & Kidney & Other organs ${ }^{\S}$ \\
\hline 1 & 39 & $\mathrm{~F}$ & Homicide & $\mathrm{X}$ & $\mathrm{X}$ & $\mathrm{X}$ & $\mathrm{X}$ & $\mathrm{X}$ & $\mathrm{X}$ & $\mathrm{X}$ & $\mathrm{X}$ \\
\hline 2 & 40 & M & Homicide & $\mathrm{X}$ & $\mathrm{X}$ & $\mathrm{X}$ & $\mathrm{X}$ & $\mathrm{X}$ & $\mathrm{X}$ & $\mathrm{X}$ & $\mathrm{X}$ \\
\hline 3 & 74 & M & Suicide & $\mathrm{X}$ & $\mathrm{X}$ & $\mathrm{X}$ & $\mathrm{X}$ & $\mathrm{X}$ & $\mathrm{X}$ & $\mathrm{X}$ & \\
\hline 4 & 21 & $\mathrm{M}$ & Suicide & $\mathrm{X}$ & $\mathrm{X}$ & $\mathrm{X}$ & $\mathrm{X}$ & $\mathrm{X}$ & $\mathrm{X}$ & $\mathrm{X}$ & \\
\hline 5 & 55 & M & Suicide & $\mathrm{X}$ & $\mathrm{X}$ & $\mathrm{X}$ & $\mathrm{X}$ & $\mathrm{X}$ & $\mathrm{X}$ & $\mathrm{X}$ & \\
\hline 6 & 36 & $\mathrm{~F}$ & Suicide & $\mathrm{X}$ & $\mathrm{X}$ & $\mathrm{X}$ & $\mathrm{X}$ & $\mathrm{X}$ & $\mathrm{X}$ & $\mathrm{X}$ & \\
\hline 7 & NAS & $\mathrm{M}$ & Homicide & $\mathrm{X}$ & $\mathrm{X}$ & $\mathrm{X}$ & $\mathrm{X}$ & $\mathrm{X}$ & $\mathrm{X}$ & $\mathrm{X}$ & $\mathrm{X}$ \\
\hline 8 & 79 & $\mathrm{~F}$ & Accidental & $\mathrm{X}$ & & & & & & & \\
\hline 9 & 63 & $\mathrm{~F}$ & Accidental & $\mathrm{X}$ & & & & & & & \\
\hline 10 & 86 & M & Accidental & $X$ & & & & & & & \\
\hline 11 & 75 & M & Accidental & $\mathrm{X}$ & $X$ & & $X$ & & & $X$ & \\
\hline 12 & 56 & $\mathrm{M}$ & Suicide & $\mathrm{X}$ & $\mathrm{X}$ & $\mathrm{X}$ & $\mathrm{X}$ & $\mathrm{X}$ & $\mathrm{X}$ & $\mathrm{X}$ & \\
\hline 13 & 23 & $\mathrm{M}$ & Accidental & $\mathrm{X}$ & & & & & $\mathrm{X}$ & $\mathrm{X}$ & \\
\hline 14 & 44 & M & Accidental & $\mathrm{X}$ & & & & & & & \\
\hline 15 & 72 & $\mathrm{M}$ & Accidental & $\mathrm{X}$ & & & & & & & \\
\hline 16 & 38 & M & Accidental & $\mathrm{X}$ & & & $\mathrm{X}$ & & & $\mathrm{X}$ & \\
\hline 17 & 27 & M & Accidental & $\mathrm{X}$ & & & & & & & \\
\hline 18 & 62 & M & Accidental & $\mathrm{X}$ & & & & & & & \\
\hline 19 & 34 & M & Accidental & $\mathrm{X}$ & & & & & & & \\
\hline 20 & 44 & $\mathrm{M}$ & Accidental & $\mathrm{X}$ & & & & & & & \\
\hline 21 & 56 & M & Accidental & $\mathrm{X}$ & & $X$ & & & & & \\
\hline 22 & 69 & M & Accidental & $X$ & & $X$ & & & & $X$ & \\
\hline
\end{tabular}

includes several sites of lesions with charred areas.

includes other charred sites: dura mater, cerebellum, aorta, esophagus, bowel e stomach.

\subsection{Parenchymatous viscera}

We used samples of brain, cerebellum, dura mater, lung, liver, spleen and kidney.

\subsubsection{Brain}

In formalin, cerebral tissue could not be histologically evaluated due to marked structural alterations caused by coagulation, charring, general fragmentation of the tissue, extensive pericellular vacuolization and marked nuclear pyknosis. Pre-treatment with Sandison's rehydrating solution showed a clear improvement of the general histological architecture of the tissue, with a good degree of conservation of the structures: vacuolization disappeared and the coagulative alterations of the white matter could not be observed anymore.

\subsubsection{Cerebellum}

In formalin, modest preservation of the cellular and histological architecture, with several lacerations of the tissue and rough vacuolization of the internal areas. Pre-treatment with Sandison's rehydrating solution eliminated lacerations and heat bubbles; the cellular component resulted to be recognizable nevertheless homogenization and nuclear pyknosis were still observable. The loss of few nuclear structures of the nervous cells could still be highlighted (Fig. 3a).

\subsubsection{Dura mater}

In formalin, marked detachment, severe alteration of the structural morphology and coagulative degeneration of the connective fibers along with nuclear pyknosis of severe stage. Pre-treatment with Sandison's rehydrating solution didn't significantly improve the histo-architectural aspect since severe alterations caused by heat could still be noted in the protein structures along with coagulative degeneration of the connective tissues and nuclear pyknosis. However, cellular morphology could be considered as improved if compared to the samples solely fixated in formalin.

\subsubsection{Lungs}

In formalin, severe complete carbonization of the pleural layer and of the superficial parenchyma, coagulation and pyknosis of the underlining pulmonary tissue, wide hemorrhagic intraalveolar foci, restriction of the alveolar septs and diffuse heat bubbles in the sub-pleural tissue. Alveolar structures appeared to be compressed and some alveolar walls collapsed. Pre-treatment with Sandison's rehydrating solution showed an improvement in the morphological structure since the pleural surface was still recognizable nevertheless the effects of heat are still observable (protein coagulation and nuclear pyknosis). A similar improvement could be observed also in the parenchymatous area where the alveolar structures were still recognizable nevertheless the alveolar spaces resulted to be dilatated of variable dimensions due to heat alterations. The compact aspect of the alveoli that could be noted in samples fixated in formal is no longer detectable (Fig. 3b).

\subsubsection{Liver}

In formalin, complete carbonization of the Glisson's capsule and of its outer layer; severe compression and fragmentation of the parenchyma, with rare isolated foci of preserved hepatocytes and of isolated areas of steatosis without alterations due to heat phenomena. Pre-treatment with Sandison's rehydrating solution allowed us to observe a modest improvement of the histological structure and a restoration of the morphological architecture of the liver. The vacuolar structures in the samples could be identified as intra-cellular, an evidence consistent with the diffuse steatosis of the organ. Only some isolated foci of hepatocytes were still characterized by cytoplasmatic alterations and nuclear pyknoses caused by heat.

\subsubsection{Spleen}

In formalin, the capsule was still recognizable with coagulated hemorrhagic foci and rough lacerations and vacuolization of the underlying parenchyma that appeared to be severely coagulated with extensive nuclear pyknosis. The parenchyma was also 

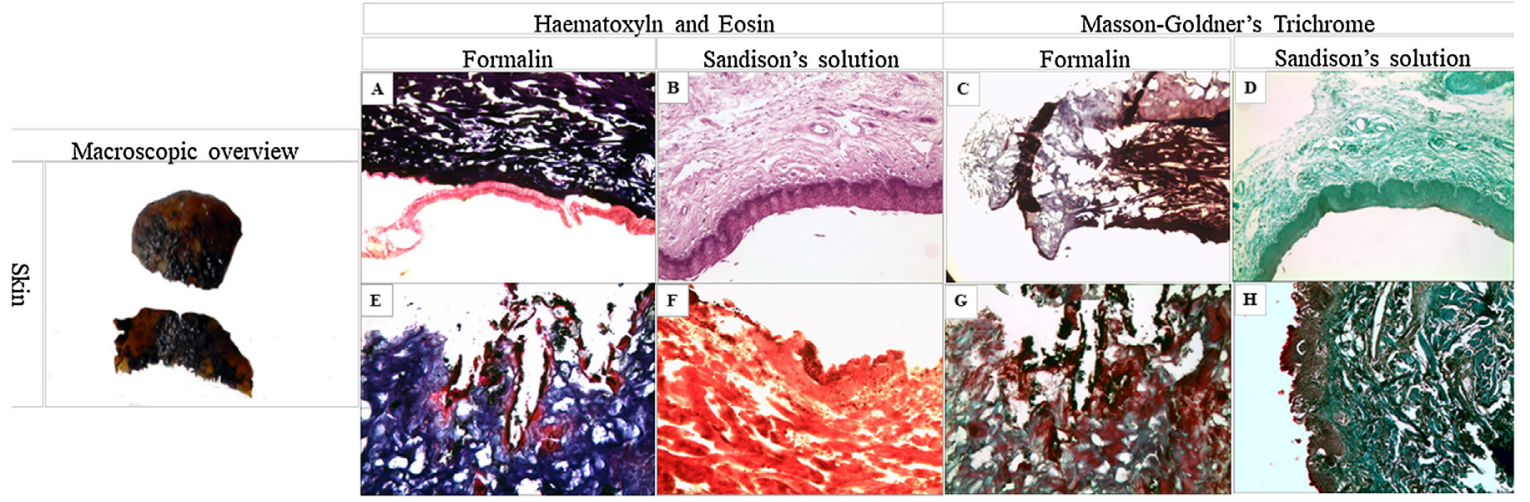

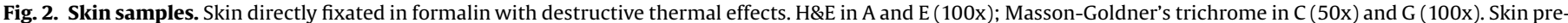

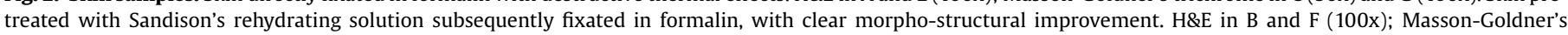
trichrome in D and $\mathrm{H}(100 \mathrm{x})$.
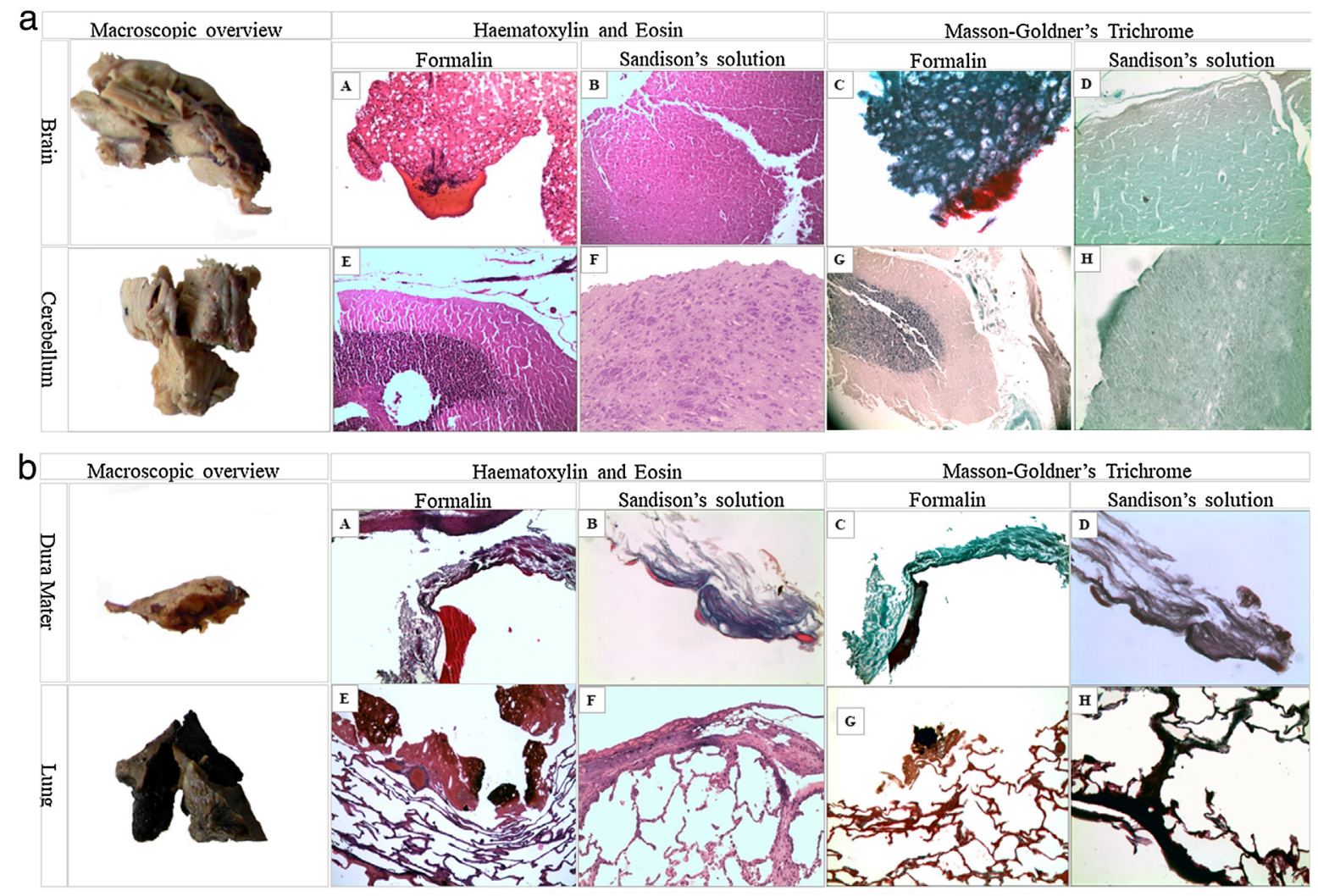

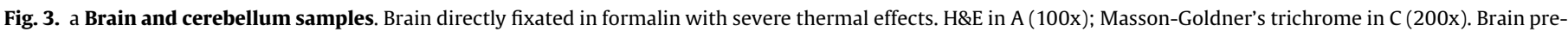

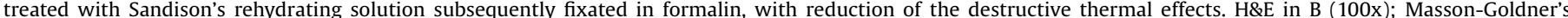

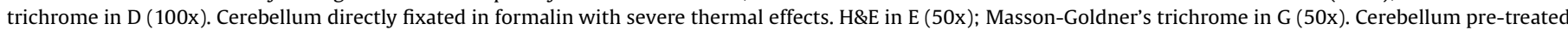

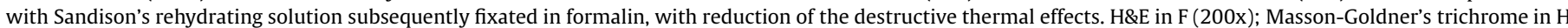

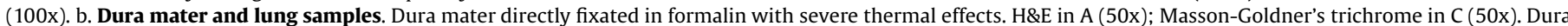

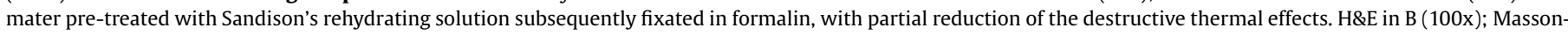

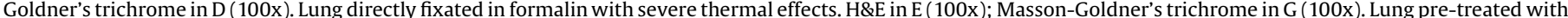

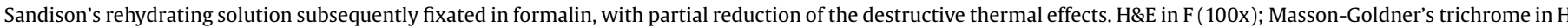

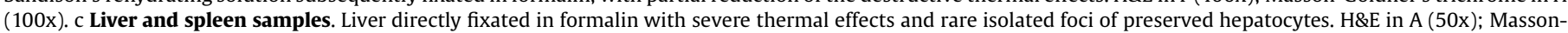

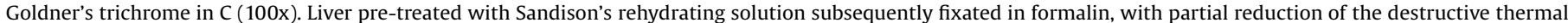

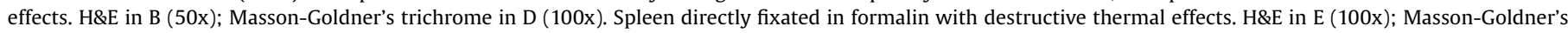

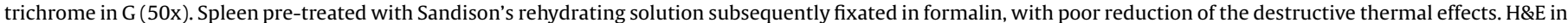

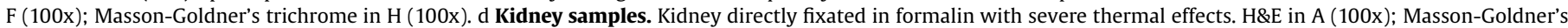

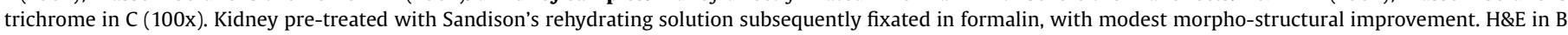
(100x); Masson-Goldner's trichrome in D (100x).

characterized by the presence of septs formed by agglomeration of altered lymphoid cells. Pre-treatment with Sandison's rehydrating solution did not show a marked improvement of the structures since the rough alterations of the capsule and of the parenchyma that could be observed in the samples fixated in formalin endured. However, some splenic septs surrounded by lymphoid follicles and small peri-trabecular lymphoid clusters could be recognized (Fig. 3c). 


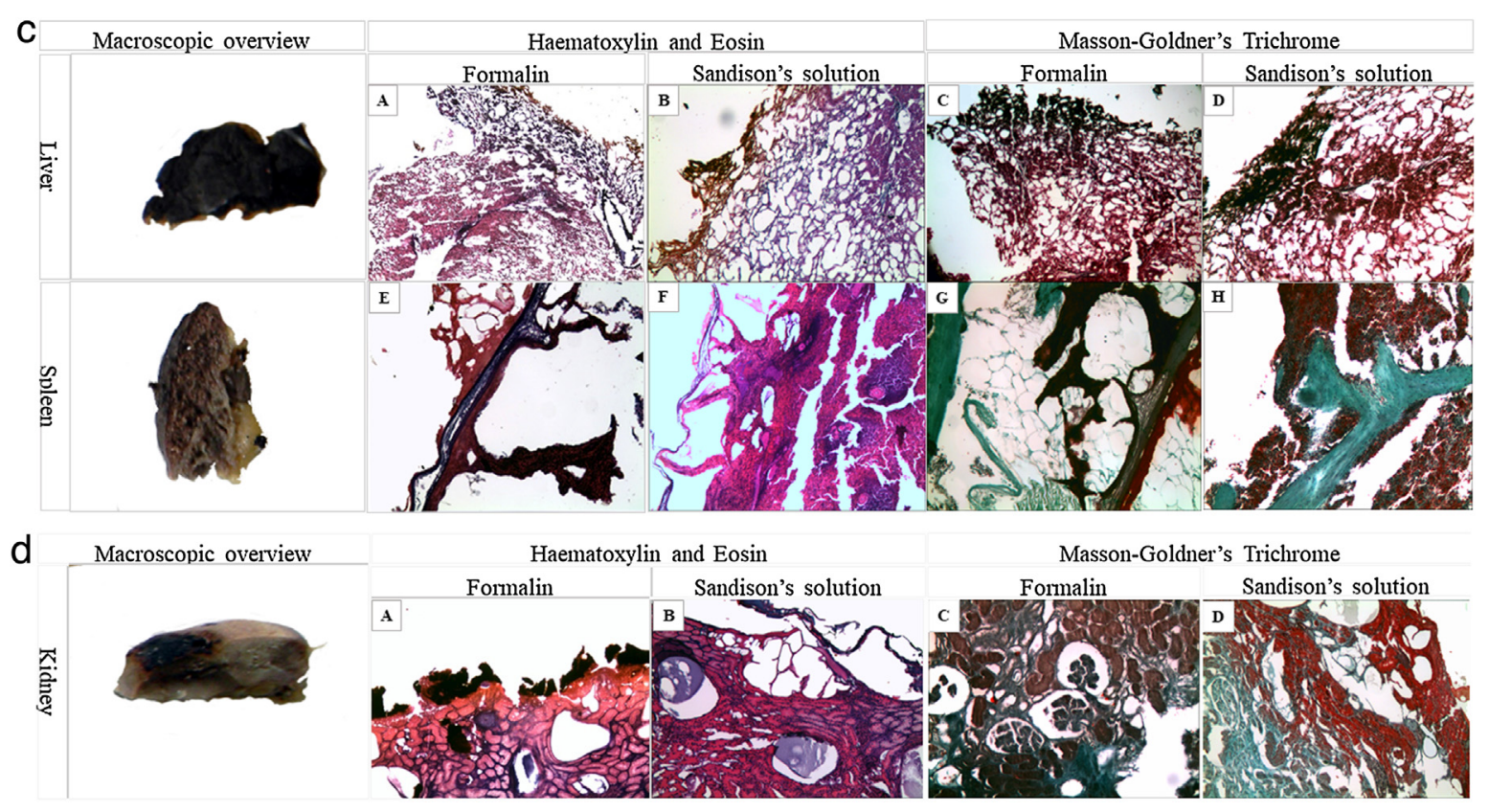

Fig. 3. (Continued)

\subsubsection{Kidney}

In formalin, wide areas of sub-capsular charring with deposition of blackish and homogeneous material. The underlining area was characterized by an extended protein coagulation with almost complete loss of the tubules (the area colored in red-orange in the microscopic samples). In the parenchyma underneath, the renal corpuscle were still recognizable with cytoplasm of homogeneous aspect and microscopic vacuoles. It was also observed the absence of the nuclei, the rough vacuolization of the parenchyma, the marked alterations and the absence of the glomeruli, associated moreover with the severe narrowing of the glomerulus capillaries. Pre-treatment with Sandison's rehydrating solution did not demonstrate a marked improvement of the sub-capsular area since the diffuse pyknosis of the nuclei and the constrained parenchyma, associated with the vacuolization of the renal tissue in the more damaged areas could still be observed. Some glomeruli, however, resulted to be more evident (Fig. 3d).

\subsection{Hollow organs}

We analyzed samples of esophagus, aorta, heart and small intestine.

\subsubsection{Esophagus}

In formalin, alterations that could be ascribed to the hardening caused by heat, with wide fragmentation and only small foci of intact muscular wall. Pre-treatment with Sandison's rehydrating solution allowed to recognize the cellular structures even though a detachment of the epithelium from the basal membrane, a coarctation and fragmentation of the sub-epithelial connective tissue and nuclear pyknosis in the areas subjected to detachment. In the areas close to carbonization, the epithelial structures appeared to be conserved.

\subsubsection{Aorta}

In formalin, rough vacuolization and iper-eosinophilic parallel stripes. This typical artifact known as "roller shatter" is caused by the excessive hardening of the tissue that produces a "jump" of the blade of a certain amount of microns during slide-cutting. Pre-treatment with Sandison's rehydrating solution allowed to recover the structure of the aorta and the artifact was not visible anymore (Fig. 4a).

\subsubsection{Heart}

In formalin, complete loss of pericardial adipose tissue caused by carbonization, marked charring, nuclear pyknosis of the endocardial muscular tissue and absence of the cellular outline. Rough vacuolization associated with coagulative alterations caused by heat were confirmed by the intense eosinophilic staining of the cytoplasm. Widespread foci of contraction bundle necrosis with confluent nuclear pyknosis forming a structure similar to a chain. Pre-treatment with Sandison's rehydrating solution did not eliminate degenerative alterations of the pericardial adipose tissue that resulted to by charred; subendocardial fibers were fragmented and bundle necrosis was particularly evident. Small foci of cellular damage similar to that observed in formalin fixation could be demonstrated (Fig. 4b)

\subsubsection{Small intestine}

In formalin, severe alterations due to heat that involved the tissue until the muscular wall and disappearance of the submucous adipose tissue. The intestinal wall was affected by rough structural alterations with charred areas, fragmented fibers and a few foci of spared wall hardly recognizable. Pre-treatment with Sandison's rehydrating solution allowed to preserve the general architecture of the intestinal villi nevertheless some marked coagulative alterations of the cells with pyknotic nuclei and charred material could be still noted. The entire muscular wall was substituted by charred material (Fig. 4c).

\section{Discussion}

The use of different rehydrating solutions is increasingly taking place in various forensic procedures: for identification protocols on mummified phalanges [6], in the entomologic field for the procedures involving Diptera larvae [7], on cadavers undergoing colorativo/emphysematous phenomena in order to evaluate the cutaneous furrow cause by hanging mechanical asphyxia [8] and 
a
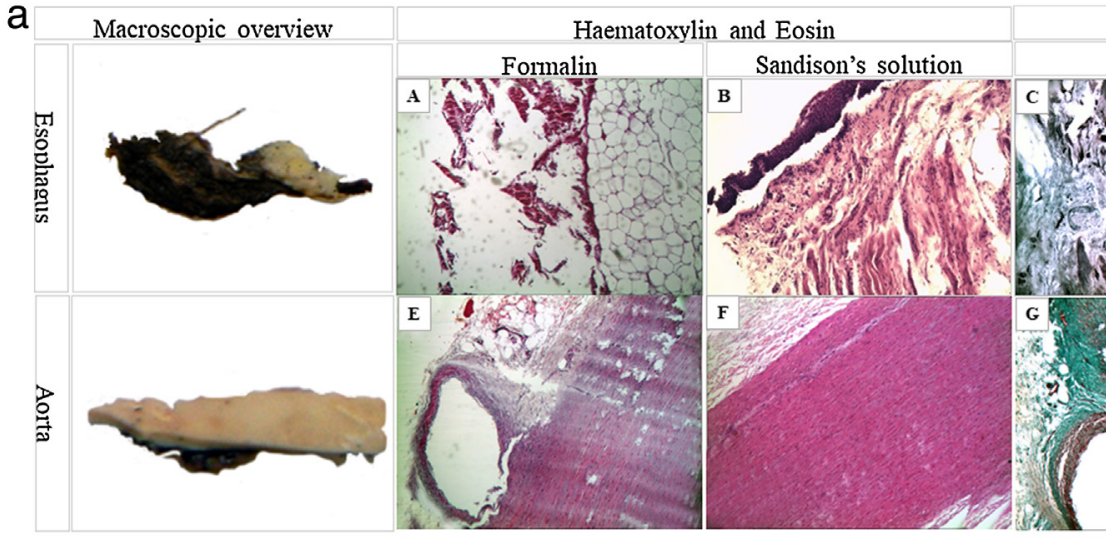

b
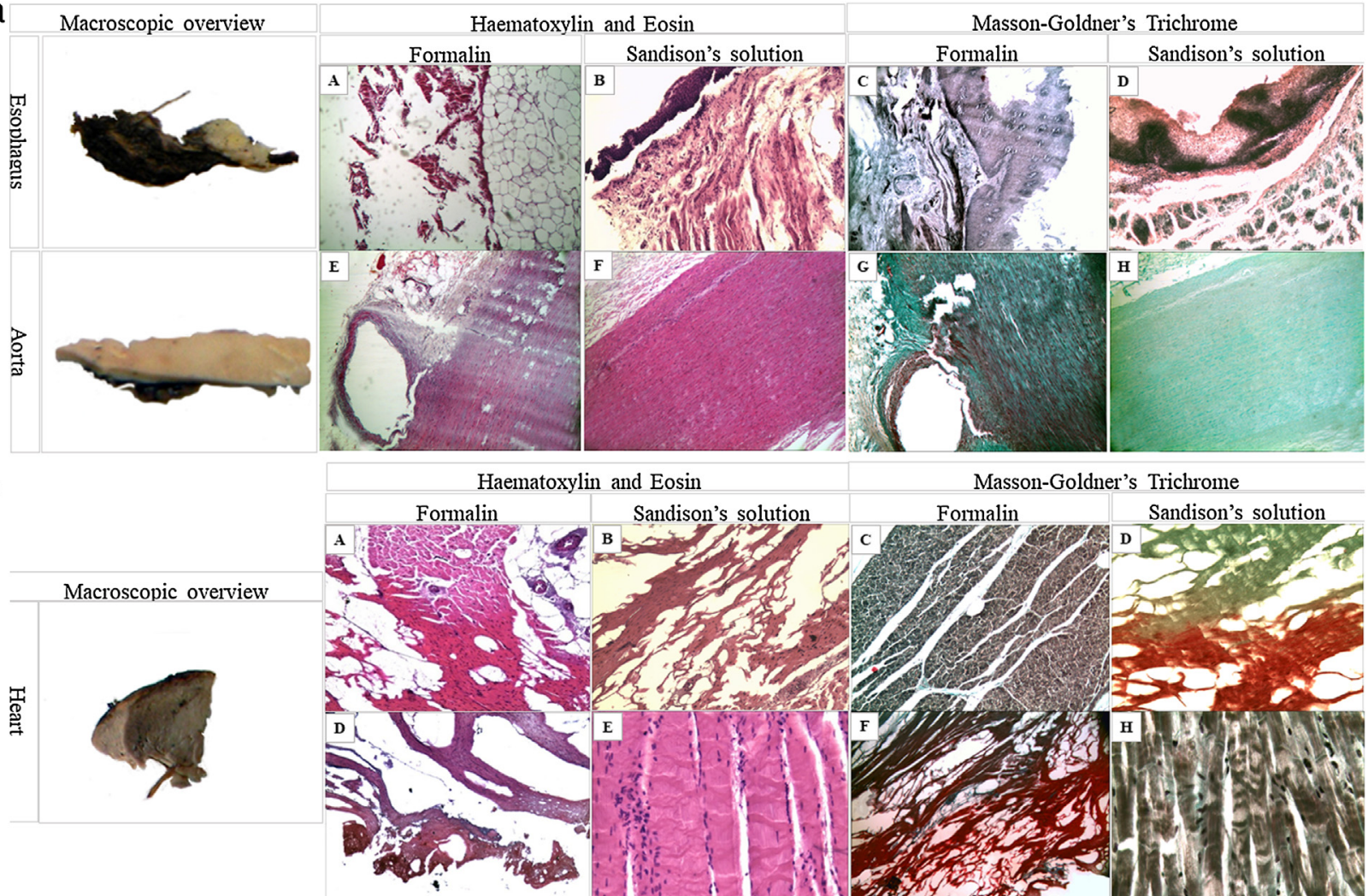

Sandison's solution

Masson-Goldner's Trichrome

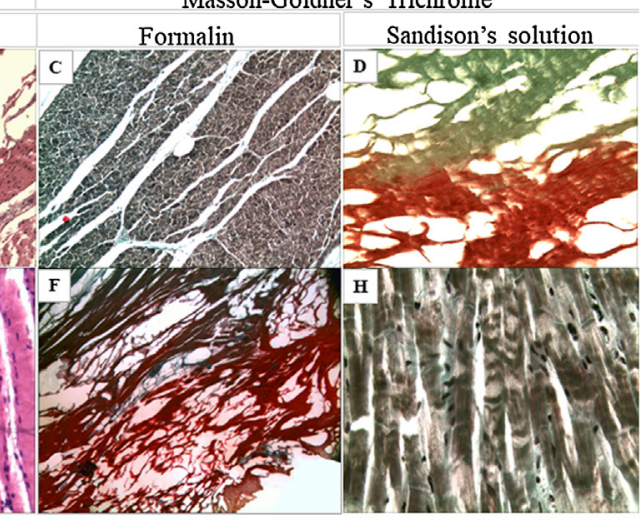

C
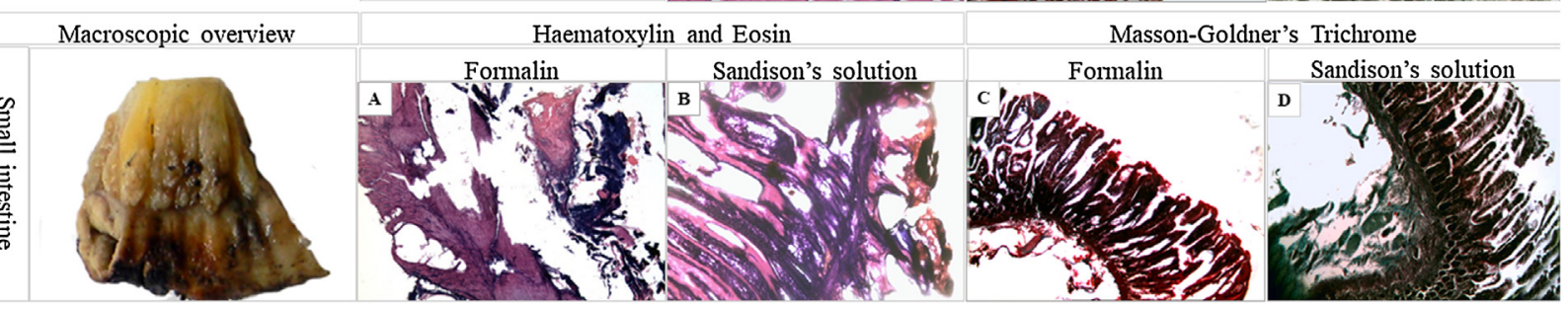

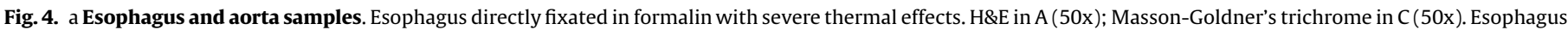

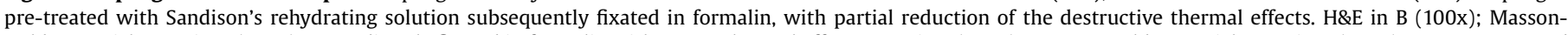

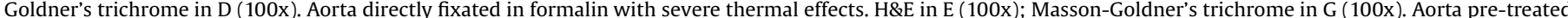

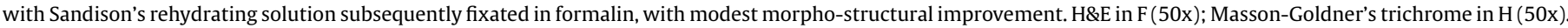

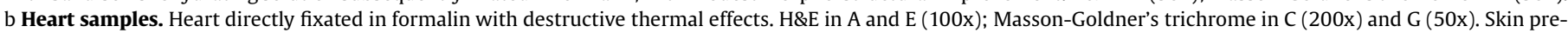

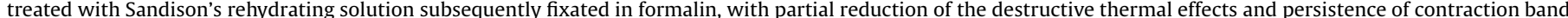

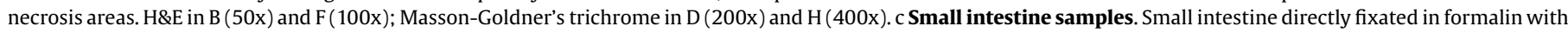

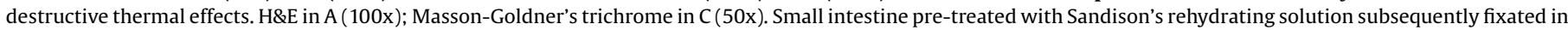
formalin, with poor reduction of the destructive thermal effects. H\&E in B (100x); Masson-Goldner's trichrome in D (100x).

on cutaneous samples undergoing peculiar putrefactive phenomena- corification and mummification [9] in order to improve the histological examination

We have applied the Sandison's rehydrating solution, for the first time ever, to cutaneous and visceral samples collected from 22 charred corpses. The histological slides observed after both H\&E and Masson-Goldner's trichrome staining, showed qualitatively superior morpho-structural aspects compared to those obtained by routine fixation with formalin. Actually, the Sandison's rehydrating solution by means of an emulsifier in it - sodium carbonate $\mathrm{Na} 2 \mathrm{CO} 3$ - penetrates deep and homogeneously into the cadaveric tissues, by means of a solvent - $96 \%$ ethanol - stabilizes the tissues and prevents their collapse and, finally, by means of a fixative - formalin - inactivates the bacteria [9]. For these reasons, this technique has determined a good improvement both of the tissue morphology and of its stainability, with the restoration of the structures and partial elimination of the artifacts related to hyper-thermal lesivity, well-known destructive lesivity.
On the whole, compared to the samples obtained by routine fixation with formalin, its use on skin samples has produced a clear improvement of the tissue morphology, on parenchymatous viscera it has partially eliminated the alterations caused by severe charring with a discreet improvement and on hollow organs it allowed a moderate regeneration of histological structures. In detail, the Sandison's rehydrating solution proved to be particularly effective on skin, brain and aorta samples; it allowed to obtain a partial histomorphological restoration of dura mater, esophagus, lung, heart liver and kidney samples; it did not allow to obtain significant improvements of spleen and small intestine samples, in which signs of heat protein coagulation, coarctations and foci of nuclear pyknosis persisted.

Considering the microscopic findings achieved in the two groups, the samples obtained after pre-treatment with Sandison's rehydrating solution are of higher quality than those fixed directly in formalin. Therefore, we consider the use of this rehydrating solution on charred cadaveric tissues to be valid, nevertheless it was observed a less morpho-structural improvement on few viscera. Actually, in all cases, 
its regenerating action has reduced, even only partially, the destructive effects induced by carbonization. In the case of charred corpses as well, as for the skin samples of mummified and corified cadavers [9], rehydration with Sandison's solution of skin and visceral samples resulted to be of simple fulfillment, low cost and a precious tool in the evaluation of these cases, characterized by marked histomorphological distortions. Based on our experience, therefore, we recommend its use in the histological approach of samples of charred skin and viscera.

\section{Declaration of Competing Interest}

The authors report no conflicts of interest. The authors alone are responsible for the content and writing of this paper.

\section{References}

[1] W. Janssen, Forensic Histopathology, Springer, Berlin, 1984.
[2] G. Umani-Ronchi, G. Bolino, A. Grande, E. Marinelli, Patologia Forense, Giuffrè Editore S.p.A. Milano, 1994.

[3] M. Tsokos, Forensic Pathology Reviews (vol.1), Humana press, Totowa, New Jersey, 2004.

[4] A. Amadasi, M. Boracchi, G. Gentile, F. Maciocco, F. Maghin, R. Zoja, Observations on self-incineration characteristics in 24 years (1993-2016) of autopsies in the city of Milan, Med. Sci. Law 58 (2018) 32-38.

[5] F. Makhlouf, J.C. Alvarez, G.L. de la Grandmaison, Suicidal and criminal immolations: an 18-year study and review of the literature, Leg. Med. Tokyo 13 (2011) 98-102.

[6] C.C. Chen, C.K. Yang, C.Y. Chen, H.C. Lee, S.M. Wang, Comparison of rehydration techniques for fingerprinting the deceased after mummification, J. Forensic Sci. 62 (2017) 205-208.

[7] M.R. Sanford, J.L. Pechal, J.K. Tomberlin, Rehydration of forensically important larval Diptera specimens, J. Med. Entomol. 48 (2011) 118-125.

[8] F. Maghin, S.A. Andreola, M. Boracchi, G. Gentile, F. Maciocco, E. Muccino, R. Zoja, Technical note: a histochemical approach in diagnosing hanging mechanical asphyxia on cadavers undergoing advanced putrefactive phenomena, Med. J. 1 (2018)25817218764754.

[9] F. Collini, S.A. Andreola, G. Gentile, M. Marchesi, E. Muccino, R. Zoja, Preservation of histological structure of cells in human skin presenting mummification and corification processes by Sandison's rehydrating solution, Forensic Sci. Int. 244 (2014) 207-212. 